This file is to be used only for a purpose specified by Palgrave Macmillan, such as checking proofs, preparing reviewing, endorsing or planning coursework/other institutional needs. You may store and print the file and share it helping you with the specified purpose, but under no circumstances may the file be distributed or otherwise made accessible to any other third parties without the express prior permission of Palgrave Macmillan.

Please contact rights@palgrave.com if you have any queries regarding use of the file.

\title{
4 \\ Fitness and Consumerism in Later Life
}

\author{
Paul Higgs and Chris Gilleard
}

\section{Introduction}

While physical exercise has conventionally been associated with masculinity and youth, changes over the last half century have seen exercise become commoditised and incorporated into the ungendered discourses of 'active ageing' (Walker, 2008). Although physical exercise has long been part of the care and cultivation of the self (Foucault, 1986), its practices and meanings have changed over time. In contemporary society, exercise has become a more 'individualised', 'fashioned' aspect of lifestyle, a set of embodied practices through which social distinction is created and interpreted beyond the barriers of age and gender. Unlike the individualistic and gendered practices associated with cosmetics, fashion and hairstyle, however, physical exercise embodies public virtue as well as the agentic nature of social citizenship (Lupton, 1995). Its role as a public good has become central to public health campaigns promoting the message that health and fitness are civic virtues to be cultivated at all ages and among all groups, a necessary part of the war against 'indolence' represented by the 'obesity epidemic' and the diseases of affluence (Campos, 2004). This combination of consumerism and the individualisation of citizenship have contributed to the transformation of exercise and fitness beyond the boundaries of age.

\section{Exercise and fitness}

Though the link between virtue and fitness has a long history, the extension of the virtuous pursuit of exercise to later life is of recent origin. Much of the early physiological research on ageing and exercise was about assessing older men's fitness for work rather than their capacity 
to live longer or live better (Ástrand et al., 1959; Botwinick and Shock, 1952; Dawson and Hellebrandt, 1945). While the 'commercialisation' of exercise and fitness was present at the beginning of the twentieth century alongside their role in equipping the state with a disciplined military and produtctive workforce, women and the old were advised against any but the gentlest forms of exercise. Throughout the late nineteenth and early twentieth century, medical literature was used to constrain young women's participation in certain sports education and the majority of sports (Vertinsky, 1987) as well as to prevent older women's enjoyment of exercise. Exercise was thought to risk 'damaging' women's reproductive capacity, while in later life 'aging women were perceived to be invalids in need of care, lacking the necessary vital energy to participate in onerous daily activities' (Vertinsky, 1991: 77). Similar negative views about men's exercise in mid and later life were expressed well into the twentieth century as men over forty were advised - and seemed to accept - that they should avoid any vigorous exercise that risked assaulting their creaking joints and 'beat up' circulatory systems (Luciano, 2001: 58).

Things changed during the course of the second half of the twentieth century with the emergence of what Turner (1984) has called the 'somatic society'. Van Hilvoorde has described this period as producing 'a culture in which people motivated by a mix of cosmetic and medical concerns voluntarily and deliberately engage in physical exercises' (2008: 1320). The rise of a dual concern with appearance and health and well-being enabled a less gendered culture of fitness to emerge, standing in sharp contrast to the previous collectivised routines that had centred on youth, war and work fitness. Now these regimes were reconstituted as individualised activities aimed at making bodies whole, healthy and attractive. All of this was increasingly appealing to a growing global market in leisure goods and services. Fitness was becoming 'postmodern'. Indeed, Glassner has argued that fitness is quintessentially a postmodern condition where the appeal of fitness products and practices offer 'the opportunity to disenthrall [one's] self from the perceived shortcomings of everyday life in modern culture in particular from constraining dualities such as expert versus amateur, self versus body, male versus female and work versus leisure (1989: 182). As a result, exercise has emerged as a desirable goal not just for youth, but for middle aged people too (Benson, 1997: 128). The 'middle-ageing' of the 'baby boomer' cohorts and their concern to stay young proved an important stimulus in this transformation, typified by the rise of aerobics, jogging and the work-out (Gilleard and Higgs, 2013: 135).

The discourses of fitness soon extended further and entered into later life. As Kagan and Morse (1988) have pointed out, previous socially 
orientated productivist and gendered concerns about fitness were 'displaced to a struggle within the body itself' where the implicit enemy was 'the body itself as it ages' (169). While the incorporation of a cosmetic and medical aesthetic into the new exercise regimes may have created new and gendered conflicts about outcomes it soon became clear that many men also shared these aspirations - especially in relation to the moral imperative to protect oneself from the ills of a society of excess by re-theorising notions of self-hood (Glassner, 1989).

The shift from collective to individualised approaches to fitness has also been seen as facilitating the commodification of exercise where exercise and fitness are seen as desirable individual goals promoting the social virtue of individualised health and fitness. Not only has exercise become an important dimension of social distinction in a somatic society, it is one that now operates as a civic imperative at all ages. Health promotion for what Deborah Lupton (1995) has termed the 'regulated body' repeatedly suggests that individual health is not only a personal concern, it is more or less a civic duty which operates through a 'will to health' that must be demonstrated at all points and in nearly all conditions. While this development has been closely identified with the rise of neo-liberal modes of health policy, it is also connected to the rise of citizenship as a form of governmentality (Higgs et al., 2009). For older people, their engagement with various 'technologies of the self' that are designed to promote fitness at later ages is set against the background of changing expectations of the norms that they are expected to reach with regard to their health and fitness. In part this is an extension of the 'polysemous' nature of the idea of fitness in a consumer society that we will explore in relation to the work of Zygmunt Bauman, but it is also a product of the collapse of the inter-relationship between normal ageing and the normativity of ageing. Older people increasingly exist in an environment where diversity is expected but which still creates normative expectations of what individuals are expected to do (Beck, 2007). Consequently, to use Mitchell Dean's distinction of the 'civilised' and the 'marginalised' (2007), we can see how a failure to engage with exercise and fitness can result in some individuals finding themselves transferred to a status of marginalisation.

\section{Bauman, consumerism and fitness}

The idea of fitness as a phenomenon of post-modernity espoused by Glassner (1989) is also explored in the work of Zygmunt Bauman. Going beyond a simple notion of fitness as an aspect of health, Bauman sees fitness as a defining feature of the somaticised consumer culture where 
the anxieties of a more contingent 'liquid modernity' are acted upon and recreated (2000). For Bauman the pursuit of fitness is much more than a peripheral aspect of people's lives, rather it acts as the organising principle for a whole range of social actions. He situates his argument by pointing out that modern society has moved from being a 'society of producers' to one that can be described as a 'society of consumers'. For him this is not just an economic transformation, it is also a thoroughgoing ontological transformation where each person's body becomes seen as the focus of individual action rather than being seen simply as a factor of production, reproduction or military might. He writes:

The postmodern body is first and foremost a receiver of sensations, it imbibes and digests experiences; the capacity of being stimulated renders it an instrument of pleasure. That capacity is called fitness; obversely the 'state of unfitness' stands for languor, apathy, listlessness, dejection, a lackadaisical response to stimuli; for a shrinking or just 'below average' capacity for, and an interest in, new sensations and experiences. (1995:116)

The 'fitness' of the postmodern body, then, is central to the practices of contemporary consumerism by setting up both discourses of 'engagement' and feelings of unease and dissatisfaction with that engagement. This has considerable benefits for a consumer culture where these feelings of dissatisfaction lead to a constant need to attempt to reach higher ideals of fitness irrespective of whatever level has been previously reached. In a significant passage Bauman writes:

'Fitness' is to a consumer in the society of consumers what 'health' was to the society of producers. It is a certificate of 'being in', of belonging, of inclusion, of the right of residence. 'Fitness' knows no upper limit; it is, in fact, defined by the absence of limit... However fit your body is - you could make it fitter. However fit it may be at the moment, there is always a vexing helping of 'unfitness' mixed in, coming to light or guessed at whenever you compare what you have experienced with the pleasures suggested by the rumors and sights of other people's joys which you have failed to experience thus far and can only imagine and dream of living through yourself. In the search for fitness, unlike in the case of health, there is no point at which you can say: now that I have reached it I may as well stop and hold onto and enjoy what I have. There is no 'norm' of fitness you can aim at and eventually attain. (2005: 93) 
This view echoes Featherstone's (1991) idea of the 'performing self' who is driven by consumption and by the moral imperative to 'not to let one's self go' in an endless quest to enhance an individual's own health and marketability. Jones and Higgs (2010) have argued that this focus meshes with the culture of the third age through the effect of continually increased expectations being placed upon individuals in order that they can demonstrate both their 'will to health' and their capacity to engage with all manner of anti-ageing techniques in order to slow the evidence and problems associated with old age. Health and social policies are no longer the main influence on health in later life and have become one aspect of the older individual's engagement with the consumer market. Ideas of 'healthy' or 'successful' ageing can also be viewed in this prism which is reconstructed as a task for the reflexive 'older' self to act agentically by making the right choices for their future wellbeing in order to age without disease, dysfunction or indeed, any diminishment of self (Higgs, 2012). As Jones and Higgs (2010) point out, the drive to demonstrate fitness at older ages becomes a new normativity separating out those capable of maintaining a position in the third age from those becoming increasingly defined by the discourses of the fourth age. Instead of an overarching 'natural' ageing accommodating all those deemed to be old, a fragmenting of the various statuses and stages of later life is encouraged by state and market alike. This is done in part to ensure that 'consumers' can be separated from 'proxy consumers' in order to maximise both market penetration for those able to demonstrate a state of agentic 'agelessness' and market optimisation for those deemed to have lost that capacity.

Because of the role that a concentration on exercise and health in later life seems to have on the moral value of old age, some gerontologists have adopted what they term an 'anti-anti-ageing' position as a way of critiquing the commoditisation of anti-ageing approaches (Vincent et al., 2008). Unlike past views about the unsuitability of exercise in later life, the new critique of exercise as 'anti-ageing' is often ambivalent about it. This view may reflect a general wish to both promote an ideal of 'healthy ageing' as an individual and public virtue while descrying the promotion of a 'fit' body in later life as a signifier of fashion driven consumerism. The anti-ageing properties of exercise are criticised for creating the narrative fiction of 'a new older adult, strong, trainable with improved psychological and health status' (Tulle, 2008: 344) which thus imagined, brings into contrast, oppresses even, those who ageing unsuccessfully demonstrate their abjection before the motif of the 'master athlete'. This conflict between acceptance of ageing and old age and those 
who have expanding possibilities of not appearing or not performing as old becomes a key line of fracture in understanding old age. Calasanti and Slevin (2001) posit this as a moral issue: Individuals not only can, but should exert control over their ageing. However, as we have seen, others see this differently. The narratives of the master athlete embody a desired extension of life not dominated by oldness and agedness, one which replaces decline with increased physical performance and the pursuit of competitive advantage displayed in the contemporary institutionalisation of 'the master athlete'.

\section{Ageing, fitness and the exercise of virtue}

Ageless physical activity is more than a deliberate tactic of seeking distinction and power through 'age resistance'. It is part of a broader social response to the changing balance between work and leisure, reflecting what Bauman has characterised as a shift from a society of producers to a society of consumers. As work as the exertion of physical labour has declined in the most prosperous nations, compensatory routines have come into play in the form of 'active' leisure which has increasingly become part of consumer society. Unlike work-dependent patterns of physical activity, active leisure can be more easily extended beyond the circumstances of working life. When the end of work meant the end of labour, more often than not it meant an inactive retirement hence retirement being framed as a tragedy or loss. But by the late 1970s and early 1980s, the inactivity of retirement was replaced by the new 'busy ethic' of leisure (Ekerdt et al., 1988). Formerly proscribed, exercise and activity in mid-life and in retirement began to be positively promoted. In 1972, less than half the Finnish population in their fifties were physically active in their leisure time; by 1992, that figure had risen to just over three quarters (Borodulin et al., 2008). No longer forced to labour, older bodies were now exercised with care, but within the context of active leisure. For those no longer working, later life has become progressively more active, with recent retirees exercising more than retirees from earlier cohorts (Agahi and Parker, 2005; Cozijnsen et al., 2014; Petersen et al., 2010).

The full extent of this change can be seen in European comparisons of sporting activity conducted a half century or so apart. In a 1953 Danish national survey of over 1000 adults, less than $10 \%$ of those aged over 50 reported any active engagement with sport, with most reporting none or only a passive engagement as spectators (Andersen et al., 1956). In 2003, the German National Health Interview found that some 30\% of men 
and $22 \%$ of women in their seventies reported participating in at least two hours of sporting activities per week, the most popular activities being cycling, gymnastics and swimming (Hinrichs et al., 2010). Numerous national surveys and reports of health and physical activity still indicate a gendered imbalance in the number of men and women engaging in sports and other deliberate physical activities, at all stages of life. But increasingly this is a difference in the pattern rather than the overall level of participation. Thus 'individualised' regimes of exercise such as walking, swimming, jogging and cycling are practiced more often by older men while aerobic, gymnastic and related group fitness activities are practiced more often by older women (Tischer et al., 2011), although there is evidence that all gender differences are declining (Borodulin et al., 2008).

The investment in the body pursued through these various exercise and sports regimes is realised in and through the market. This may include going to commercial organisations such as private gyms, leisure centres, aerobic dance classes or various not-for-profit social clubs or using commercial products such as workout regimes on videos or DVDs, computer exercise games, smart phone 'activity and fitness' applications, cycling, rowing or similar fitness machines, treadmills and other forms of exercising machinery. Some form of 'home trainer' for example can be found in over 30\% of later life German households (Gilleard and Higgs, 2011: 365). While pensioners clubs and other local government settings may still offer free fitness classes, such settings can be seen as the failed choices of the marginalised rather than the preferred later life styles of successful consumers.

Fitness is consequently more than the exercise of a consumerist interpellation. If one pursues the idea that ageing is at bottom no more than the consequence of an inadequate genetic investment in the soma, as Kirkwood among others have implied (Kirkwood, 1997), compensating for this lack of genetic investment by investing in a refashioned lifestyle seems a logical response. Within the paradigm of what Gilleard and Higgs (2013) have called 'the new ageing', exercise and fitness oriented practices can be seen as deliberate social and cultural investment in embodied practices oriented toward not becoming old. The success of which is both a source of distinction and individualised moral virtue.

\section{Conclusions}

The pursuit of fitness in later life has become part of the new ageing ethic embodied in the ideals of active, productive or successful ageing. 
In this chapter, we have used the term 'exercise' to cover what are in fact a wide variety of embodied practices ranging from body building to walking, marathon running to step and dance aerobics. What distinguishes the physical exercise regimes of first modernity from those of second modernity is the latter's individualisation, commercialisation and integration into the broader 'lifestyles' of those no longer young. In other words, becoming part of consumer society. Jogging and aerobics, home trainers and DVD fitness exercises, computerised 'activity' games and the complex electronic devices used to monitor progress target the individual consumer of all ages are all part of the evidence of the role of consumption in constructing fitness. The expanding keep fit industry vastly overshadows that of the old-fashioned body building regimes of Eugen Sandow in the 1900s and the 'dynamic tension' methods promoted by Charles Atlas in the dying decades of first modernity.

The individualisation of fitness has also promoted, or at least facilitated, less exclusionary practices with respect both to gender and age. Aerobics, jogging, marathons and work-outs are as accessible to those in mid and later life as they are to those still young and, increasingly, as much to women as to men (Tischer et al, 2011). This is true not just for the more 'cosmetic' forms of fitness involved in work-outs and aerobics, but for those activities where master athletes compete. Over the last three decades, for example, older women have increased their participation in the New York City marathon, more than any other demographic group (Lepers and Cattagni, 2012.

As exercise oriented body-work has moved from the realms of production to those of leisure and consumption, it has more easily been incorporated into leisured later lifestyles. While the forms of physical activity undertaken by older bodies are still connected with the embodied identities of gender, race and disability, they are less connected to the productive processes of society. Their old embodied identities do not so much constrain as segment the market. This is not to ignore that as participation in exercise and fitness becomes an expanding new virtuous 'norm', issues of distinction become issues of marginalisation, as failure to demonstrate an engagement with health promoting forms of exercise becomes a marker of a personal failure to become self-constituting and agentic (Jones and Higgs 2010). Following Lupton's 'imperative of health' (1995), whatever the personal outcome, it is necessary to acknowledge the reality of the cultural shift towards the need to 'exercise' the body in later life irrespective of the consequences that follow.

It is also important to recognise that there is no single discourse associated with exercise, just as there is no single consumerist voice. The 
practice of fitness is polysemous. It is shaped by history as much as by gender or chronological age. It reinforces some aspects of identity as well as undermining or denying others. Exercise can be seen as part of the anti-ageing enterprise, an alternative cosmetics of the body, colluding with and reinforcing a fear of ageing that permeates the cultures of second modernity (Vincent et al., 2008: 293). At the same time, it can be seen as part of modern bio politics whereby the internalisation of bodily standards and regimes enables responsibility for one's own 'bodily good condition' to be shifted from the state and society to the individual and his or her household (Higgs et al, 2010). But, as Phoenix and Smith (2011) have pointed out, the 'counter-stories' of master athletes can also contribute to 'new aging identities' that can 'evoke social change in the way that aging is interpreted and given meaning' (637). Viewed in this light, exercise represents a form of performativity resisting the performer's objectification as 'aged' and his or her oppression by the community of 'old age' (Sims-Gould et al., 2010). Adopting one of Foucault's later formulations, exercise and physical activity can be seen as part of the agonistic exploration both of what human bodies can be, and what they can become (Foucault, 1982). And of course exercise can also be a way of people having fun, enjoying being a body that both performs and serves a positive sense of self without reference to age (Tulle, 2008).

\section{References}

Andersen H, Bo-Jensen A, Elkǽr-Hansen N and Sonne A (1956) Sports and games in Denmark in the light of sociology. Acta Sociologica 2(1): 1-27.

Ástrand I, Ástrand PO and Rodahl K (1959) Maximal heart rate during work in older men. Journal of Applied Physiology 14: 562-566.

Bauman Z (1995) Life in Fragments. London: Basil Blackwell.

Bauman Z (2000) Liquid Modernity. Cambridge: Polity.

Bauman Z (2005) Liquid Life. Cambridge: Polity.

Beck U (2007) Beyond class and nation: reframing social inequalities in a globalizing world. The British Journal of Sociology 58(4): 679-705.

Benson J (1997) Prime Time: A History of the Middle Aged in Twentieth-Century Britain. London: Longman.

Borodulin K, Laatikainen T, Juolevi A and Jousilahti P (2008) Thirty-year trends of physical activity in relation to age, calendar time and birth cohort in Finnish adults. European Journal of Public Health 18(3): 339-344.

Botwinick J and Shock, NW (1952) Age differences in performance decrement with continuous work. Journals of Gerontology 7(1): 41-46.

Calasanti TM and Slevin KF (2001) Gender, Social Inequalities and Aging. Walnut Creek, California: AltaMira Press. 
Campos PF (2004). The obesity myth: Why America's obsession with weight is hazardous to your health. New York: Penguin.

Cooper KH (1970) New Aerobics. New York: Bantam Press.

Dean M (2007) Governing Societies. Buckingham, UK: Open University Press.

Dinnerstein M and Weitz R (1994) Jane Fonda, Barbara Bush and other aging bodies: femininity and the limits of resistance. Feminist Issues 14(2): 3-24.

Foucault M (1982) The subject and power. In: HL Dreyfuss and P Rabinow (eds) Michel Foucault: Beyond Structuralism and Hermeneutics. Hemel Hempstead, UK: Harvester Wheatsheaf, pp. 208-226.

Foucault M (1986) The History of Sexuality, Volume Three: The Care of the Self $\mathrm{R}$ Hurley (trans). London: Penguin Books.

Gilleard C and Higgs P (2011) Consumption and aging. In: R Setterson and JL Angel (eds) Handbook of Sociology of Aging. New York: Springer, pp.361-375.

Gilleard C and Higgs P (2013) Ageing, Corporeality and Embodiment. London: Anthem Press.

Glassner B (1989) Fitness and the postmodern self. Journal of Health and Social Behavior 30(6): 180-191.

Higgs P (2012) Consuming bodies: Zygmunt Bauman on the difference between fitness and health. In G Scambler (ed) Contemporary Theorists for Medical Sociology. London: Routledge, pp. 20-32.

Higgs P, Leontowitsch M, Stevenson F and Jones IR (2009) Not just old and sick: the will to health in later life. Ageing and Society 29:687-707.

Hinrichs T, Trampisch U, Burghaus I, Endres HG, Klaaßen-Mielke R, Moschny A, et al. (2010) Correlates of sport participation among community-dwelling elderly people in Germany: a cross-sectional study. European Review of Aging and Physical Activity 7: 105-115.

Jones IR and Higgs P (2010) The natural, the normal and the normative: contested terrains in ageing and old age. Social Science and Medicine 71(8): 1513-1519.

Kagan E and Morse M (1988) The body electronic: aerobic exercise on video: women's search for empowerment and self-transformation. TDR 32(4): $164-180$.

Kirkwood T (1997) The origins of human ageing. Philosophical Transactions of the Royal Society of London Series B-Biological Sciences 352(1363): 1765-1772

Lepers R and Cattagni T (2012) Do older athletes reach limits in their performance during Marathon running? Age 34(3):773-81.

Luciano L (2001) Looking Good: Male Body Image in Modern America. New York: Hill and Wang.

Lupton D (1995) The Imperative of Health: Public Health and the Regulated Body. London: Sage.

Phoenix C and Smith B (2011) Telling a (good?) counter story of aging: natural bodybuilding meets the narrative of decline. The Journals of Gerontology, Series B: Psychological and Social Sciences 66(5): 628-639.

Sims-Gould J, Clarke LH, Ashe MC, Naslund J and Liu-Ambrose T (2010) Renewal, strength and commitment to self and others: older women reflections of the benefits of exercise using Photovoice. Qualitative Research in Sports and Exercise 2(2): 250-266.

Tischer U, Hartmann-Tews I and Combrink C (2011) Sport participation of the elderly: the role of gender, age and social class. European Review of Aging and Physical Activity 8(1): 83-91. 
Tulle E (2008) Acting your age? sports science and the ageing body. Journal of Aging Studies 22(4): 340-347.

Turner BS (1984) The Body and Society. Oxford: Basil Blackwell.

Van Hilvoorde I (2008) Fitness: the early (Dutch) roots of a modern industry. The International Journal of the History of Sport 25(10): 1306-1325.

Vertinsky P (1987) Exercise, physical capability and the eternally wounded woman in late nineteenth century North America. Journal of Sport History 14(1): 7-27.

Vertinsky P (1991) Old age, gender and physical activity: The biomedicalization of aging. Journal of Sport History 18(1): 64-80.

Vincent J, Tulle E and Bond J (2008) The anti-aging enterprise: science, knowledge, expertise, rhetoric and values. Journal of Aging Studies 22(4): 291-294.

Walker A (2008) Commentary: the emergence and application of active aging in Europe. Journal of Aging and Social Policy 21(1): 75-93. 